\title{
Imagens em avalia-ação: uma pesquisa- ação sobre o uso de matérias televisivas em aulas de educação física
}

\section{Images in evalua(c)tion: research-action on the use of television programs in physical education classes}

\author{
Mauro Betti ${ }^{1}$
}

\begin{abstract}
RESUMO
O objetivo desta investigação foi elaborar e experimentar procedimentos avaliativos que buscaram acessar as aprendizagens propiciadas em aulas de Educação Física que se valeram de matérias televisivas. A metodologia utilizada foi a pesquisa-ação. Concluiu-se que os alunos aprofundaram sua percepção e entendimento sobre o tema desenvolvido nas aulas ("exclusão/ discriminação"); que as estratégias utilizadas contemplaram uma avaliação integrada ao processo de ensino e aprendizagem; e que o uso da matéria televisiva escolhida deu-se de forma integrada ao processo, caracterizandose como imprescindível para o seu desenvolvimento.

Palavras-chave: Educação Física escolar; mídia; televisão; avaliação; pesquisa-ação.
\end{abstract}

\begin{abstract}
The goal of this research was to elaborate and experiment evaluation procedures that sought to access the learning offered in Physical Education classes which made use of TV programs as matter and teaching strategy. The methodology used was the research-action. The conclusion was that the students deepened their perception and understanding on the topic developed at classes ("exclusion/discrimination"); that the strategies used concerned an integrated evaluation in the process of teaching and learning; and that the use of the TV program chosen was essential for their development.

Keywords: physical education; media; television; evaluation; research-action.
\end{abstract}

1 Doutor em Filosofia da Educação, Professor Adjunto do Departamento de Educação Física da Faculdade de Ciências da Universidade Estadual Paulista - Campus de Bauru, Brasil. E-mail: mbetti@fc.unesp.br. 


\section{Introdução}

Desde meados da década de 1980, se tem apresentado na Educação Física brasileira proposições teórico-metodológicas de caráter progressista ou crítico (BRACHT, 1999), que buscam superar as concepções e práticas pautadas na esportivização (BETTI, 2009a) e na aptidão física (CASTELLANI FILHO et al., 2009), fortemente fundamentadas na biologia e na ideia do corpo como máquina. Ao final da década de 1990, os estudos sobre as mídias ${ }^{2}$ adentram este cenário de modo mais intenso, com a preocupação de explicitar fenômenos e reflexões acerca das influências dos diversos meios e tecnologias de informação e comunicação sobre a Educação Física, bem como indicações para sua incorporação nas práticas pedagógicas dessa disciplina escolar e na formação inicial dos professores da área (BETTI; PIRES, 2005).

$\mathrm{O}$ argumento básico gira em torno do fato de que as mídias, em especial a televisão, exercem influência crescente e decisiva sobre a cultura corporal de movimento ${ }^{3}$, informando e ditando formas, construindo novos significados e modalidades de entretenimento e consumo, em especial no caso do esporte e da ginástica/exercício físico, embora outras formas da cultura corporal de movimento também apareçam como objeto do processo de espetacularização mediado pelas câmaras televisivas, como temática da publicidade, como matéria de investigação e notícias em jornais, revistas e sites da internet. Com isso, a cultura corporal de movimento, inclusive em seus aspectos técnico-científicos, tornou-se publicamente partilhada, alcançando "praticantes" e "não-praticantes". Todavia, o que as mídias propiciam, num primeiro momento, é um grande mosaico sem estrutura lógica aparente, composta de informações desconexas, em geral, descontextualizadas, e recebidas individualmente. O que se pretende é desenvolver nos alunos a capacidade de associar informações desconexas, analisá-las e aprofundá-las. Porque a Escola deve ser um lugar de conexões, de comunicação entre os homens, na qual a individualização e o parcelamento dos

2 Por "mídias" entendemos os tradicionais meios de comunicação de massa, como jornal, rádio, televisão etc., assim como as novas Tecnologias da Informação e Comunicação ("TICs"), que incluem as tecnologias e instrumentos usados para armazenar e compartilhar informações mediante o uso de redes de computadores e convergência de outros equipamentos (internet, telefone celular etc.).

3 Por "cultura corporal de movimento" entendemos, com base em Betti (2009b), aquela parcela da cultura geral que abrange as formas culturais que se vêm historicamente construindo, nos planos material e simbólico, mediante a exercitação sistemática e intencional da motricidade humana: particularmente, no caso da tradição da Educação Física, referimo-nos aos jogos, esportes, ginásticas e práticas de aptidão física, atividades rítmicas/expresssivas e dança, lutas/artes marciais, bem como práticas corporais emergentes e não-tradicionais . 
conhecimentos corrigem-se - enfim, lugar de reflexão crítica coletiva (BABIN; KOULOUMDJIAN, 1989).

Tal fenômeno alcança a Educação Física Escolar, e cabe a essa disciplina propiciar a apropriação crítica da cultura corporal de movimento (BETTI, 2009b), os produtos e processos das mídias devem ser objetos e meios de educação, visando preparar os alunos para estabelecerem com elas uma relação crítica e criativa. Betti (2001) sintetiza possíveis vantagens do uso da linguagem audiovisual das mídias no ensino da Educação Física: (i) motiva o debate e a reflexão, por tratar de assuntos atuais e polêmicos, sobre os quais em geral os alunos já possuem informações; (ii) as produções midiáticas são atraentes aos alunos, pois a linguagem audiovisual faz parte da cultura infanto-juvenil; (iii) conseguem dar destaque e importância para informações que às vezes o próprio professor transmite mas não obtém repercussão satisfatória; (iv) sintetizam muito conteúdo em pouco tempo, e podem substituir com vantagem aulas expositivas ou textos escritos. Com base em Morán (1995), sugerimos que o uso de produções midiáticas no ensino da Educação Física poderia atender aos seguintes objetivos: (i) sensibilização: quando se quer introduzir um novo assunto, para despertar a curiosidade, a motivação para novos temas (por exemplo, uma prática corporal ainda desconhecida para os alunos); (ii) ilustração: para ajudar a mostrar o que se fala em aula, a compor cenários desconhecidos para os alunos, trazer realidades distantes (por exemplo, documentários sobre a história do esporte); (iii) conteúdo de ensino: mostra determinado assunto de forma direta, quando informa sobre um tema específico orientando sua interpretação; ou de forma indireta, quando permite abordagens múltiplas ou interdisciplinares sobre o tema (por exemplo, documentários investigativos sobre doping no esporte e academias de musculação). Em uma fase mais avançada, os próprios alunos poderiam produzir textos audiovisuais, que abordassem suas experiências, necessidades e interesses nas relações com a cultura corporal de movimento. Isto possibilitaria também melhor compreensão da própria linguagem das mídias, que envolve a seleção de imagens e falas, de enquadramentos etc.

É necessário, então, pesquisar e propor metodologias adequadas para a efetiva incorporação das produções das mídias ao ensino da Educação Física. Tais tarefas têm sido enfrentadas em vários estudos (BETTI, 2003, 2006, 2007; BATISTA; BETTI, 2005, 2009b; OLIVEIRA; PIRES, 2005; LISBOA, 2007; MENDES; PIRES, 2009) que indicaram possibilidades para a inserção de matérias televisivas ou a viabilização de produções midiáticas por parte dos próprios alunos no desenvolvimento de temas selecionados em programas de Educação Física escolar.

A literatura oriunda da denominada "mídia-educação" (por exemplo: FERRÉS, 1996; OROZCO-GOMES, 1997; BELLONI, 2001; BUCKINGHAM, 
2002; FANTIN, 2006; RIVOLTELLA, 2005) tem propiciado parte importante da fundamentação teórico-metodológica desses estudos, nos quais o uso de uma produção televisiva, ou a produção de imagens por parte dos alunos, não apareceram como fins em si mesmos, mas subordinados a um projeto de Educação Física escolar. É também no contexto dessa tarefa engajada que esta investigação se insere.

Dentre as conclusões mais importantes de estudos que realizamos anteriormente nessa temática (BETTI, 2006, 2007), podemos destacar:

- As matérias/programas televisivos utilizados nas aulas de Educação Física devem estar inseridos no desenvolvimento de um tema/conteúdo, ao qual se integram as atividades corporais vivenciadas nas aulas, e relações com a vida cotidiana dos alunos;

- Os professores destacaram a necessidade das matérias/programas televisivos prenderem a atenção dos alunos, de modo a evitar o desinteresse e consequente dispersão;

- A estratégia predominante nas aulas baseou-se na tentativa de estabelecer um "debate" verbal após a exibição dos vídeos, debate este que, em maior ou menor grau, foi monopolizado pelo professor;

- Os professores optaram majoritariamente pelo uso de uma matéria televisiva específica, pela segurança proporcionada por experiências anteriores na sua utilização, por facilitar o desenvolvimento de conteúdos conceituais, e por tratar a referida matéria de um tema que permitiria despertar o interesse dos alunos, por ser constantemente "pautado" nas mídias e constituir-se em preocupação constante dos adolescentes;

- A análise das aulas indica que os professores prenderam-se aos conteúdos mais óbvios da matéria, reforçando as "recomendações" para a saúde nela presentes. Dimensões interpretativas mais profundas não foram explicitamente abordadas. Então, a concepção que vê na Educação Física a finalidade de apropriação crítica da cultura corporal de movimento apareceu nessas aulas mais como apropriação de alguns conteúdos conceituais do que como crítica - quer dizer, como exame dos critérios que subjazem a esses conteúdos, das opções valorativas que eles implicam.

Betti (2007) relata que o tema da avaliação dos alunos tornou-se cada vez mais visível ao longo da pesquisa-ação empreendida. As aulas que se valeram de matérias televisivas para apoiar o desenvolvimento dos temas, possibilitaram que aprendizagem aos alunos? Como avaliar essa aprendizagem? Essas foram questões recorrentes. Foi possível perceber que os professores utilizaram estratégias "informais" e não sistematizadas (comentários, alusões e citações feitos 
pelos alunos sobre as matérias televisivas); e estratégias mais “formais" e sistematizadas de avaliação (provas, produção de textos e trabalhos de "pesquisa").

Os professores participantes da investigação de Betti $(2006,2007)$ alertaram para as dificuldades de avaliar a aprendizagem por meio de instrumentos que se valem da linguagem escrita (provas, produção de textos), pois, na medida em que tais instrumentos exigem a explicitação de conceitos presentes nos vídeos utilizados, os alunos antecipam as respostas que o professor considerará "corretas". Então, não é possível saber se de fato o aluno concorda com o que escreveu, ou se o conhecimento supostamente adquirido implicará em mudanças de atitudes e condutas em sua vida cotidiana. Seria preciso, portanto, concretizar uma avaliação que não fosse uma "falsa impressão", conforme as palavras de um dos professores participantes.

Propôs-se, então, passar da avaliação dos vídeos, em termos da sua pertinência para a inclusão em aulas de Educação Física, para a avaliação de aprendizagens que poderiam desencadear em temas selecionados.

Assim, o objetivo desta pesquisa foi elaborar e experimentar procedimentos avaliativos que buscaram acessar algumas dimensões das aprendizagens propiciadas em aulas de Educação Física no ensino fundamental que se valeram de matérias/programas televisivos, na perspectiva da Educação Física concebida como apropriação crítica da cultura corporal de movimento.

\section{A dinâmica metodológica: pesquisa-ação}

Os objetivos e a natureza da investigação demandaram uma metodologia descritiva e interpretativa que possibilitasse o diálogo com os fundamentos teóricos de uma Educação Física concebida como apropriação crítica da cultura corporal de movimento. Tais exigências levaram a eleger a pesquisa-ação, com amparo nas proposições de Thiollent (1986), Elliott (1990, 1993) e Pereira (1998).

Segundo Pereira (1998), a pesquisa-ação em educação surgiu nos anos 1960 como uma tentativa (dos acadêmicos) de superar as lacunas existentes entre o ensino e a pesquisa, e de resolver o problema da relação entre teoria e prática. Com diferentes ênfases, pretende ao mesmo tempo conhecer (pesquisa) e atuar (ensino), e, portanto, superar a distância entre pesquisador e professor.

Thiollent (1986, p. 14) define a pesquisa-ação como: 
um tipo de pesquisa social com base empírica que é concebida e realizada em estreita associação com uma ação ou com a resolução de um problema coletivo e no qual os pesquisadores e os participantes representativos da situação ou do problema estão envolvidos de modo cooperativo ou participativo.

Tal ação, alerta Thiollent (1986), é não trivial, quer dizer, é uma ação problemática, merecendo investigação para ser elaborada e conduzida; trata-se de pesquisa na qual as pessoas envolvidas têm participação ativa, e na qual há uma exigência de conhecimento a ser produzido.

No entendimento de Elliott (1993), no campo da educação, a pesquisa não pode estar separada da prática; a prática mesma é a forma de investigação, e a produção teórica deve derivar das tentativas de mudar as práticas, e estas são o meio pelo qual se elaboram e comprovam as suas próprias teorias, ou seja, as práticas constituem-se em categorias de hipóteses a comprovar.

Elliott (1990), então, define a pesquisa-ação como uma atividade empreendida por grupos humanos com o objetivo de modificar suas circunstâncias a partir de valores compartilhados; é uma prática reflexiva, com ênfase social, bem como o processo de investigar sobre ela.

Segundo Pereira (1998), a pesquisa-ação caracteriza-se como um processo que se modifica continuamente em espirais de reflexão e ação, e que, ao invés de limitar-se a utilizar um saber existente (o que caracterizaria a pesquisa aplicada), busca mudanças no contexto concreto e estuda as condições e os resultados da experiência efetuada. $\mathrm{O}$ objetivo não é simplesmente resolver um problema prático da melhor forma, mas, pelo delineamento do problema, compreender e melhorar a atividade educativa; preocupa-se, portanto, com a mudança da situação e não só com sua interpretação. Tal característica confere então à pesquisa-ação uma dimensão ética.

Outro aspecto lembrado por Pereira $(1998$, p. 168) é o fato de que a pesquisa-ação reforça a postura colaborativa dos professores que, ao refletirem suas práticas, "trabalham dialogicamente com seus colegas e não deixam de lado a influência das estruturas curriculares".

A concepção de pesquisa-ação tal como defendida por Elliott $(1990,1993)$ recomendou, para o presente estudo:

- A necessidade de, sem negar as divergências, haver algum compartilhamento de valores com relação ao entendimento de Educação Física escolar, o que parece ter sido garantido nas fases anteriores da pesquisa (BETTI, 2003, 2006, 2007); 
- Não criar uma situação artificial para a "testagem" isolada de estratégias e conteúdos de ensino, mas sim integrá-los no conjunto de aulas que objetivam desenvolver um determinado tema;

- O entendimento de que a necessidade de produzir conhecimentos sobre o uso de matérias televisivas como estratégia e conteúdo de ensino não pode sobrepor-se ao compromisso de produzir melhorias nas práticas pedagógicas, nos termos dos valores compartilhados.

Participaram seis professores (doravante designados interlocutoresprofessores - IP), sendo cinco oriundos da pesquisa anterior, e um novo. Foram desenvolvidas 11 reuniões de trabalho, divididas em duas etapas: $1^{\text {a }}$ ) estudo da literatura relativa ao tema "avaliação", e planejamento dos procedimentos da nova proposta de pesquisa; e $2^{\mathrm{a}}$ ) relato e discussão das aulas realizadas.

A descrição das aulas, os registros filmados e a produção escrita dos alunos, resultante das estratégias utilizadas, foram apresentados e debatidos nas reuniões de trabalho, nas quais se procurou instaurar, mediante uma interlocução argumentativa (THIOLLENT, 1986) - diálogo de caráter construtivo, em que os interlocutores buscam conjuntamente as soluções - o processo de reflexão-ação entre os professores participantes.

Nesse sentido, preferimos vislumbrar a pesquisa-ação não como uma "intervenção" na prática pedagógica, palavra que carrega inevitavelmente uma conotação autoritária, mas em interlocução, em duplo sentido: do pesquisador com os professores participantes, e destes com a sua prática. Daí a opção por denominar os professores participantes desta pesquisa de "interlocutores-professores".

\section{Resultados}

"Mas professor, precisa mesmo fazer avaliação de Educação Física?" "Precisa, eu quero saber o que você entendeu” (IP-1): o desafio da avaliação

O estudo da literatura sobre avaliação incluiu obras de Luckesi (1994), Zabala (1998) e Gimeno-Sacristán (1998).

A afirmação de Gimeno-Sacristán (1998, p. 295) evidencia bem a complexidade do tema da avaliação no ensino: "Estudar a avaliação é entrar na análise de toda a pedagogia que se pratica", pois a prática da avaliação é condicionada por aspectos pessoais, sociais e institucionais, e ao mesmo tempo incide sobre todos os elementos envolvidos na escolarização: transmissão de conhecimentos, relações entre professores, alunos e família, interações no grupo, métodos, disciplina etc. 
As tendências mais recentes indicam a necessidade de superar a prática tradicional de avaliação, na qual esta se apresenta separada da aprendizagem e realiza-se ao final de um ciclo de ensino, mediante um ato formal e explícito de comprovação, dotado de suposta objetividade (uma prova, por exemplo), perdendo assim "seu valor formativo no diálogo crítico entre professores/as e alunos/as" (GIMENO-SACRISTÁN, 1998, p. 339).

A avaliação pode ser definida como um julgamento de valor, a partir de dados relevantes para a tomada de decisões (LUCKESI, 1994). A atribuição de conceitos implica num julgamento sobre a qualidade do trabalho dos alunos, que se dá a partir de informações sobre eles, e da percepção genérica sobre o seu desempenho global. A metodologia de ensino adotada pelo professor é determinante, em grande parte, dos indícios selecionados pelo professor como relevantes para, a partir deles, chegar a um julgamento. A mediação, que transforma as informações disponíveis (geralmente condutas ou trabalho materialmente observável) em conceitos é um processo cognitivo-profissional peculiar a cada professor, cujos critérios são de difícil explicitação, porque envolvem crenças e valores (GIMENO-SACRISTÁN, 1988).

Contudo, algumas questões podem ser encaminhadas. É preciso que o professor considere a amplitude da avaliação: o que avaliar no aluno? As concepções mais progressistas propõem a avaliação da totalidade do aluno, e o rendimento ideal não é só intelectual, mas considera aspectos amplos da personalidade, como as facetas afetiva, social e corporal. De modo geral, houve na educação escolarizada uma ampliação do que se considera objeto da avaliação. Como contrapartida, sua realização prática fica dificultada, e também passa a exigir um amadurecimento geral do pensamento do professor, na medida em que as crenças e valores, que são menos explícitas, adquirem mais importância como mecanismos mediadores (GIMENO-SACRISTÁN, 1988).

Nessa perspectiva, Zabala (1998) e Gimeno-Sacristán (1998) argumentam em favor de uma avaliação integrada/integradora, formativa e holística/globalizadora. A avaliação integrada é a que ocorre durante o processo de ensino e aprendizagem, "como um processo natural de informação sobre o que acontece, que utiliza múltiplos recursos, sem estabelecer necessariamente procedimentos formais de avaliar, ou seja, de conhecer o aluno/a" (GIMENO-SACRISTÁN, 1998, p. 340); depende, fundamentalmente, das capacidades dos professores compreenderem situações, reações dos alunos, níveis de realizações, dificuldades que apresentam etc. A avaliação é formativa porque considera que o processo avaliador "tem que observar as diferentes etapas de uma intervenção que deverá ser estratégica" e possibilitar "uma compreensão e valoração sobre o processo seguido, que permita estabelecer novas propostas de intervenção" (ZABALA, 1998, p. 201). É holística/globalizadora porque contempla "como finalidade fundamental do ensino a formação integral da pessoa" (ZABALA, 
1998, p. 201); considera o aluno "como ser que está aprendendo, por isso é globalizadora de toda sua personalidade, holística (abrange tudo)" (GIMENOSACRISTÁN, 1998, p. 342).

Desse modo, ganham importância, além da autoavaliação, os procedimentos informais (por exemplo, a observação em contextos "naturais" da aula), que geram informações (indícios) de natureza qualitativa, os quais necessitam de interpretação e valoração por parte dos professores, e portanto dependem de suas capacidades e esquemas de percepção, além das atividades propostas aos alunos, que devem permitir a expressão do que se deseja avaliar.

Assim, Gimeno-Sacristán (1998, p. 298) adota uma definição ampla de avaliação, que compartilhamos:

Avaliar se refere a qualquer processo por meio do qual alguma ou várias características de um aluno/a, de um grupo de estudantes, de um ambiente educativo, de objetivos educativos, de materiais, professores/as, programas etc., recebem a atenção de quem avalia, analisam-se e valorizam-se suas características e condições em função de alguns critérios ou pontos de referência para emitir um julgamento que seja relevante para a educação.

Destaca-se nessa concepção um importante aspecto da avaliação: ela não se restringe à avaliação do aluno, e, mesmo neste caso, não tem como única finalidade atribuir-lhe conceitos/notas. Portanto, entendemos que, em primeiro lugar, a avaliação deve servir para problematizar e aperfeiçoar a prática pedagógica, em detrimento das funções de certificação, seleção, hierarquização de excelências e poder de controle. É importante destacar, com Zabala (1998), que a avaliação deve estar sempre referida às aprendizagens dos alunos. Na mesma direção, Elliott (1993) entende que a base da avaliação do ensino está nos dados do processo mais que do produto, e o aluno se constitui na fonte fundamental desses dados. Para Gimeno-Sacristán (1998) tal concepção de avaliação está em consonância com os paradigmas de pesquisa que buscam melhorar as práticas educativas, dentre as quais incluímos a pesquisa-ação.

Portanto, o desafio que aqui se coloca é o de acessar as aprendizagens dos alunos por meio de procedimentos avaliativos que estejam em consonância, conforme as palavras de Gimeno-Sacristán (1998), com os "critérios ou pontos de referência" do projeto pedagógico que sustenta tais programas, qual seja, a Educação Física concebida como apropriação crítica da cultura corporal de movimento. Como o referido entendimento de Educação Física implica a arti- 
culação entre vivência/conhecimento/reflexão das diversas manifestações da cultura corporal de movimento, qualquer proposição de avaliação neste âmbito exigirá sua integração ao processo de ensino e aprendizagem.

"Tem que haver uma vinculação entre o objetivo que você traça, o conteúdo que você trabalha e a avaliação" (IP-3): a construção das estratégias avaliativas

Ao apontar a imprescindível coerência que deve haver entre objetivos, conteúdos e avaliação, o IP-3 destacou ainda como se relacionam a "uma concepção que você tem de Educação Física". Tal fala sintetizou o direcionamento do estudo: avaliação integrada ao processo de ensino e aprendizagem, e a impossibilidade de separar dimensões conceituais, procedimentais e atitudinais, o que seria incompatível com a Educação Física concebida como apropriação crítica da cultura corporal de movimento.

Houve consenso que muitos alunos pouco ou nada expressam verbalmente nas aulas, que as opiniões/conclusões da maioria, a respeito do tema em debate, tendem a convergir para a "média" ou consenso do grupo, e que, em instrumentos de avaliação escritos, os alunos tendem a explicitar o que julgam que o professor considera "correto". Então, como expressou o IP-1: "a gente não sabe ao certo nem como ele avalia aquela aula, nem como entendeu aquilo [...], na verdade a gente tem poucos dados".

Não sem polêmicas, pois o aluno "está habituado a receber nota $[\ldots]$ o professor está habituado a dar nota" (IP-1), prevaleceu a orientação da literatura de que deveria haver desvinculação das estratégias a serem escolhidas da atribuição de conceitos aos alunos. Tal orientação também guardou relação com o objetivo principal da investigação, já que se pretendia prioritariamente experimentar procedimentos avaliativos em relação a aulas de Educação Física nas quais matérias televisivas fossem nucleares, ou seja, sem elas o processo não seria possível tal como ocorreu.

A partir dessas referências principais, um conjunto de estratégias foi elaborado em conjunto por pesquisador e interlocutores-professores.

Como "a gente escolhe o vídeo muito de acordo com o que tá acontecendo na escola no momento" (IP-1) optou-se por um tema ("discriminação/exclusão") e uma matéria televisiva ${ }^{4}$ que os interlocutores-professores identificaram como relevante para o seu contexto, já que a discriminação dos alunos menos habi-

4 Trata-se do episódio "Pernas de Pau", do seriado Anos Incríveis, produção norte-americana cuja história gira em torno das relações entre o personagem principal, um adolescente de 12 anos, e seu melhor amigo, que é vítima de discriminação/exclusão nas aulas de Educação Física, por conta de seu menor nível de habilidade na prática do Basquetebol. 
lidosos por parte dos demais era problema com que todos se defrontavam em suas aulas, e porque não se restringia à dimensão conceitual de conteúdos, mas implicava questões de atitudes, valores e concepções de Educação Física e esporte.

Decidiu-se que as estratégias deveriam contemplar uma avaliação diagnóstica, exibição da matéria televisiva, discussão e nova avaliação. Uma aula "piloto" foi desenvolvida por um dos interlocutores-professores, incluindo redação inicial de questões com finalidade de avaliação diagnóstica. O modo de resolução do conflito do episódio por parte dos personagens principais (recusarem-se a prosseguir na competição esportiva, em favor da amizade de irmãos) foi destacado, e indagou-se aos alunos o que fariam na mesma situação. O IP-4, responsável pela aula-piloto, informou que $48 \%$ dos alunos responderam que fariam o mesmo, e $37 \%$ que prosseguiriam na disputa, com as mais variadas justificativas.

A discussão em torno desta aula-piloto indicou a necessidade de, entre a avaliação diagnóstica e a avaliação final, haver outras atividades relacionadas ao tema, e não apenas um debate relativo ao episódio televisivo, mesmo que estas "atividades" pudessem influenciar a compreensão dos alunos, e assim obscurecer a relação causa-efeito entre assistência ao vídeo e mudanças de atitude/ opinião na segunda avaliação, já que o objetivo prioritário não seria avaliar o vídeo em si, mas as aprendizagens desencadeadas nas aulas que dele se valeram.

Foi definido, então, que, inicialmente, seria criada uma situação em aula (escolha de times e posterior jogo de basquetebol) para evidenciar a exclusão/discriminação de alguns alunos menos habilidosos. Tal situação seria registrada em câmara de vídeo. A filmagem seria então apresentada aos alunos e, a seguir, os alunos deveriam responder, por escrito e identificados por pseudônimos, a questões pré-elaboradas sobre suas percepções e entendimentos da situação: (1) Você percebeu algum tipo de discriminação (na escolha dos times e durante o jogo)?; (2) Você se sentiu discriminado? Por quê?; (3) Como você acha que uma pessoa discriminada se sente?

O episódio do seriado televisivo que tratava de situação similar seria então exibido, seguido de discussão com os alunos e resposta a uma nova bateria de questões, sobre possíveis soluções que poderiam ser encaminhadas para eliminar a exclusão/discriminação nas aulas: (1) De que maneira podemos fazer a escolha dos times para que não haja discriminação?; (2) Existe uma forma de jogar em que todos participem e ninguém se sinta discriminado? Como seria?

\section{"Respondeu: sim, porque ninguém tocava a bola pra mim"(IP-2): as aulas e as respostas dos alunos}

Essas estratégias foram desenvolvidas por dois interlocutores-professores, em duas escolas, e parte do processo foi registrado em câmara de vídeo. 
O IP-1 relatou as duas aulas desenvolvidas com uma turma de $7^{\mathrm{a}}$ série, as quais tomaram parte em um conjunto maior de aulas, que teve o Basquetebol como conteúdo. Informou inicialmente que pôde identificar a autoria de muitas respostas, pois houve alunos que não fizeram questão de manter anonimato mediante uso de pseudônimo, como havia sido proposto. Sua análise das respostas indicou que a maioria dos alunos identificou algum tipo de discriminação na escolha dos times e durante o jogo, exceto por parte daqueles mais habilidosos, que na verdade discriminaram os outros. Cerca de metade dos alunos se sentiram discriminados, na escola e/ou durante o jogo. Muitas alunas (foi possível identificar o sexo em função das próprias respostas), em particular, sentiram-se discriminadas por dois motivos: porque foram as últimas a serem escolhidas, e porque os meninos não passavam a bola para elas durante o jogo. Uma destas alunas sugeriu "deixá-los fora do time, ou seja, os bons assistirem a aula enquanto os ruins jogam, pra eles verem o quanto é ruim eles ficarem sem participar do jogo". Quase todos usaram adjetivos "negativos" com relação aos sentimentos de uma pessoa discriminada, como "triste", "sem confiança", "sozinha", "envergonhada" etc.

Já na segunda rodada de questões, em outra aula, após assistirem e discutirem sobre o episódio televisivo, o IP-1 relatou que as sugestões dos alunos para haver maior participação e menor discriminação permitiram identificar dois grupos. Os que se sentiram discriminados sugeriram que houvesse no jogo um caráter de "brincadeira", de "amizade", de "coletividade", ou então que o critério de divisão dos times fosse o sexo ("os meninos são brutos [...], não passam a bola pras meninas"), a amizade ("escolhendo por amizade não teria tanto problema de querer ganhar um jogo"), ou aleatório ("camisa branca pra cá $[\ldots]$ calça preta pra lá").

Segundo o IP-1, algumas dessas sugestões refletiam práticas já consagradas em suas aulas, que buscavam aumentar a participação dos alunos. Já os mais habilidosos, embora tenham percebido alguma discriminação, sugeriram a divisão dos times por níveis de habilidade ("bons" e "ruins"), pois entenderam que todos precisam esforçar-se, para conseguir jogar melhor, e portanto não se viam como responsáveis pela discriminação: "pra eles seria uma forma de fazer um jogo mais justo, onde não haveria discriminação". Já para os alunos que se sentiram discriminados, a discriminação decorre da ideia de que os mais habilidosos devem aceitar os menos habilidosos, os quais teriam "que passar a bola pra todo mundo".

O IP-2 optou por desenvolver a escolha dos times e o jogo de basquetebol apenas com alunos do sexo masculino de uma turma de $8^{\mathrm{a}}$ série, para controlar a variável sexo, mas todos responderam às questões. Apenas dois alunos responderam que se sentiram discriminados, mas todos perceberam, a partir da assistência ao vídeo, cenas de discriminação na escolha dos times e/ou durante o 
jogo: "ninguém passava a bola para eles, deixavam eles correrem que nem "tontos", "foi o último a ser escolhido, porque não sabia jogar muito bem". Os sentimentos das pessoas discriminadas foram descritos em termos de rejeição, tristeza, mal-estar, humilhação, mágoa, desânimo, desprezo etc. As sugestões para evitar a discriminação referiram-se à necessidade do professor intervir na escolha, adaptação de regras, escolha aleatória dos times, fazer acordos, jogar em equipe, valorização da brincadeira, do divertimento, entre outros.

O IP-2 acrescentou ao questionário da segunda etapa a questão "O que você aprendeu ao assistir este vídeo?" (referindo-se ao episódio "Pernas de Pau"). Foram recorrentes as respostas como: "ganhar nem sempre é melhor, o importante é se divertir", "amizade em $1^{\circ}$ lugar", "que não se deve discriminar as pessoas".

"O que eles passam na quadra é significativo pra eles, eles sentem o que acontece" (IP-1): a interpretação das aulas

Para o IP-1, o vídeo proposto foi perfeitamente integrado ao conteúdo que vinha desenvolvendo com a turma: "eles já tinham pesquisado a história do basquete, já tinham vivenciado o basquete". A este mesmo IP chamou atenção $o$ fato de os alunos terem constantemente se referido às cenas de discriminação - presentes tanto no vídeo da atividade desenvolvida em quadra, como no episódio televisivo -, e como perceberam a semelhança entre as duas situações, fato também descrito pelo IP-2.

O IP-1 também entendeu que os vídeos "atingiram o objetivo proposto", que talvez "provocamos mudança na forma de pensar do aluno", mas "não necessariamente nas atitudes, na forma de viver dele na quadra, no dia a dia dele". Contudo, o mesmo IP, e outros, admitiram que têm observado, mesmo que de modo parcial e fragmentado, mudanças nas condutas dos alunos em aula, o que atribuem à influência do trabalho realizado já há alguns anos, no qual os vídeos têm servido como "alavanca", conforme definiu o IP-2. Para o IP-1, como "o que ele [aluno] sentiu corporalmente vivenciando aquela situação é tão significativo quanto aquele que apreciou lá no vídeo"; então "em termos de comparação de respostas, as duas levam pro lado da discriminação - ele se sentiu, ele se percebeu, ele viu no vídeo da classe, e ele também conseguiu localizar isso daí no jogo". Para o IP-2, no segundo questionário, houve "um tipo de resposta mais elaborada, uma reflexão mais aprofundada"

Podemos interpretar tal fato a partir do "método compreensivo" proposto por Ferrés (1996) para a análise crítica de programas televisivos, pois a assistência ao episódio televisivo, $\mathrm{e} o$ ato de responder às questões propostas, teriam proporcionado o "segundo tempo" a que se refere Ferrés: o momento de elaboração reflexiva sobre o vivido e assistido, que vai além do impacto emocional inicial. 
O IP-2 também valorizou as sugestões dos alunos para eliminar a exclusão/ discriminação, e afirmou que o professor deve ser "o mediador do processo [...] de provocar conflito, de problematizar pra que se encontre uma solução".

\section{Conclusão}

Concluiu-se, pela comparação das respostas nos dois momentos, e por indícios colhidos em observações informais, que os alunos puderam refletir e aprofundar sua percepção e entendimento sobre a exclusão/discriminação na Educação Física. As inúmeras e coerentes sugestões dos alunos para a minimização da discriminação também evidenciam que houve adequada compreensão do tema por parte destes. Contudo, os interlocutores-professores não se permitiram estabelecer relação de causa-efeito entre os vídeos e mudanças de valores e atitudes dos alunos, já que a avaliação da mudança de condutas só poderia se dar no longo prazo, e com muita dificuldade para serem observadas e registradas. Mas acreditam que têm conseguido provocar estas mudanças nos alunos com quem convivem há mais tempo.

Considerou-se que as estratégias utilizadas contemplaram os princípios recomendados na literatura para uma avaliação integrada ao processo de ensino e aprendizagem, e que, conforme recomendação oriunda das fases anteriores da pesquisa (BETTI, 2003, 2006, 2007), o uso dos vídeos (tanto a filmagem da escolha dos times e do jogo, como o episódio televisivo) deu-se de forma incorporada ao processo, o que foi imprescindível para o seu desenvolvimento das aulas e do tema em questão. Por fim, sugerimos que a pesquisa-ação pode contribuir para a aproximação entre ensino e pesquisa, à medida que os participantes vão alargando os ciclos de ação e reflexão, mantendo como foco as práticas educativas.

\section{REFERÊNCIAS}

BABIN, P.; KOULOUMDJIAN, M. F. Os novos modos de compreender: a geração do audiovisual e do computador. São Paulo: Edições Paulinas, 1989.

BATISTA, S. R.; BETTI, M. A televisão e o ensino da educação física na escola: uma proposta de intervenção. Revista Brasileira de Ciências do Esporte, Campinas, v. 26, n.2, p. 7-180, 2005. 
BELlONI, M. L. O que é mídia-educação. São Paulo: Autores Associados, 2001. (Polêmicas do nosso tempo, 78)

BETTI, M. Imagem e ação: a televisão e a educação física escolar. In: BETTI, M. (Org.). Educação Física e mídia: novos olhares, outras práticas. São Paulo: Hucitec, 2003, p. 91-137.

BETTI, M. Mídias: aliadas ou inimigas da educação física escolar? Motriz, Rio Claro, v.7, n.2, p. 125-129, jul./dez. 2001.

BETTI, M. "Imagens em ação": uma pesquisa-ação sobre o uso de matérias televisivas em programas de educação física do ensino fundamental e médio. Movimento: Revista da Escola de Educação Física, Porto Alegre, v. 12, n.2, p.95-120, maio/ago. 2006.

BETTI, M. Das “imagens em ação" às "imagens em avalia-ação": uma pesquisaação sobre o uso de matérias televisivas em programas de educação física escolar. In: CONGRESSO BRASILEIRO DE CIÊNCIAS DO ESPORTE, 15., CONGRESSO INTERNACIONAL DE CIÊNCIAS DO ESPORTE, 2., Recife. Anais... Recife: Colégio Brasileiro de Ciências do Esporte, 2007, p. 1-10.

BETTI, M. Educação física e sociedade: a educação física na escola brasileira. 2. ed. rev. São Paulo: Hucitec, 2009a.

BETTI, M. Educação física escolar: ensino e pesquisa-ação. Ijuí: Ed. Unijuí, 2009 b.

BETTI, M.; PIRES, G. de L. Mídia. In: GONZÁLEZ, F. J.; FENSTERSEIFER, P. E. (Org.). Dicionário crítico de educação fisica. Ijuí: Editora Unijuí, 2005, p. 282-288.

BRACHT, V. A constituição das teorias pedagógicas da educação física. Cadernos Cedes, Campinas, v. 19, n. 48, p. 69-88, 1999.

BUCKINGHAM, D. Crecer en la era de los medios electrónicos: tras la muerte de la infancia. Madrid: Morata, 2002.

CASTELLANI FILHO, L. et al. Metodologia do ensino da educação física. 2. ed. rev. São Paulo: Cortez, 2009.

ELLIOTT, J. La investigación-acción en educación. Madri: Morata, 1990.

ELLIOTT, J. El cambio educativo desde la investigación-acción. Madri: Morata, 1993.

FANTIN, M. Mídia-educação: conceitos, experiências, diálogo Brasil-Itália. Florianópolis: Cidade Futura, 2006. 
FERRÉS, J. Televisão e educação. Porto Alegre: Artes Médicas, 1996.

GIMENO-SACRISTÁN, J. A avaliação no ensino. In: GIMENO-SACRISTÁN, J.; PÉREZ-GÓMEZ, A. I. (Org.). Compreender e transformar o ensino. 4. ed. Porto Alegre: Artmed, 1998, p. 295-351.

GIMENO-SACRISTÁN, S. El curriculum: una reflexión sobre la práctica. Madrid: Morata, 1988.

LISBOA, M. M. Representações do esporte-da-mídia na cultura lúdica de crianças. 122 f. Dissertação (Mestrado em Educação Física) - Centro de Desportos, Universidade Federal de Santa Catarina, Florianópolis, 2007.

LUCKESI, C. C. Avaliação da aprendizagem escolar. Cortez: São Paulo, 1994.

MENDES, D. de S.; PIRES, G. de L. Desvendando a janela de vidro: relato de uma experiência escolar de mídia-educação e educação física. Revista Brasileira de Ciências do Esporte, Campinas, v. 30, n. 3, p. 79-94, maio 2009.

MORAN, J. M. O vídeo na sala de aula. Comunicação e Educação, São Paulo, v.2, p. 27-35, 1995.

OLIVEIRA, M. R. R. de; PIRES, G. de L. O primeiro olhar: experiência com imagens na educação física escolar. Revista Brasileira de Ciências do Esporte, Campinas, v. 26, n. 2, p. 117-133, jan. 2005.

OROZCO-GÓMEZ, G. O. Professores e meios de comunicação: desafios, estereótipos. Comunicação e Educação, São Paulo, v. 3, n. 10, p. 57-68, 1997.

PEREIRA, E. M. de A. Professor como pesquisador: o enfoque da pesquisa-ação na prática docente. In: SERALDI, C. M. G.; FIORENTINI, D.; PEREIRA, E. M. de A. (Org.). Cartografias do trabalho docente: professor(a)-pesquisador(a). Campinas: Mercado das Letras, ALB, 1998. p. 153-182.

RIVOLTELLA, P. C. Media education: fondamentti didattici e prospective di ricerca. Brescia: La Scuola, 2005.

THIOLLENT, M. Metodologia da pesquisa-ação. São Paulo: Cortez, Autores Associados, 1986.

ZABALA, A. A prática educativa. Porto Alegre: ArtMed, 1998.

Texto recebido em 19 de fevereiro de 2010.

Texto aprovado em 07 de abril de 2010. 